\title{
Non-steroidal anti-inflammatory drugs and the chemoprevention of colorectal and oesophageal cancers
}

In recent years, several areas of biological research have increasingly supported the suggestion that aspirin and other non-steroidal anti-inflammatory drugs (NSAIDs) may reduce the occurrence or progression of colorectal and, to a lesser extent, oesophageal cancer or both. This suggestion is supported by consistent biochemical, pharmacological, toxicological, clinical, and epidemiological messages. This leading article reviews the evidence and demonstrates how these diverse studies can be translated into strategies for NSAID intervention trials in cohorts at risk of colorectal and oesophageal cancer.

\section{NSAIDs and colorectal cancer}

In 1977, Bennett et al ${ }^{1}$ noted increased concentrations of prostaglandins in colorectal cancer tissue when compared with normal colorectal mucosa. Given the pharmacological ability of NSAIDs to inhibit the cyclooxygenase (COX-1) enzyme and thereby block prostaglandin synthesis, several research groups (notably Pollard and Luckert and Narisawa et al) soon considered the effects of NSAIDs on chemically induced cancers in rodents. Landmark studies then showed that NSAIDs could both prevent and reverse colorectal adenomas and carcinomas. ${ }^{23}$ Since then more than 20 studies have been published and nearly all have confirmed the original reports. Indeed, the chemopreventive properties of several NSAIDs including aspirin, ${ }^{4}$ indomethacin, ${ }^{5}$ piroxicam, ${ }^{6}$ and sulindac ${ }^{7}$ have been shown.

Clinical experience with NSAIDs included a series of case reports ${ }^{89}$ and randomised trials, ${ }^{1011}$ which demonstrated the ability of sulindac to reduce the size and number of colorectal polyps occurring in patients with familial adenomatous polyposis (FAP). These findings have important public health implications as it is likely that the adenoma/carcinoma sequence in FAP patients is similar to that of the general population. This concept is supported by recent epidemiological findings of a $40 \%-50 \%$ reduction in mortality from colorectal cancer among subjects regularly taking NSAIDs compared with those not taking these agents. ${ }^{12-20}$ Two further clinical trials designed to test screening and antioxidant strategies for colorectal cancer have found decreased risks of colorectal adenomas among regular aspirin users. ${ }^{21} 22$ None of these studies have provided information regarding optimum dose and frequency of aspirin use. To obtain data that can be translated into intervention strategies, future epidemiological studies should consider the relations between aspirin consumption, baseline cancer risk, and the resultant adenoma/carcinoma incidence.

Although these independent lines of research all support the link between NSAID use and colorectal cancer, the pharmacological basis of NSAID protection remains unclear. Protection is probably multifactorial and could be related to the ability of NSAIDs to arrest colorectal carcinogenesis at several stages. In low-moderate risk patients, the ability of NSAIDs to augment tumour immunosurveillance mechanisms $\mathrm{s}^{23}$ may be sufficient to prevent cancer while in moderate-medium risk patients, NSAIDs may arrest carcinogenesis directly within the colorectal mucosa. There is a biochemical basis for this suggestion because the colorectal mucosa metabolises arachidonic acid predominantly via a lipoxygenase pathway ${ }^{24}$ to form leukotrienes. The colorectal mucosa is thus associated with a low prostaglandin/leukotriene ratio, however, colorectal carcinogenesis is associated with progressive increases in mucosal prostaglandin E2 synthesis. ${ }^{25}$ NSAIDs may arrest this carcinogenic stage by inhibiting prostaglandin E2 synthesis and diverting the arachidonic acid cascade into lipoxygenase metabolism. Biochemically, this would parallel a restoration of the low prostaglandin/ leukotriene ratio. In medium-high risk patients, NSAIDs may arrest carcinogenesis using a combination of these properties. Furthermore, there are indications that NSAIDs stimulate programmed cell death (apoptosis) in vitro ${ }^{26}$ and in FAP patients. ${ }^{27}$ Rodent models of colorectal cancer provide good experimental models to examine the effects of NSAIDs upon apoptosis. In high risk carcinoma in situ patients, NSAIDs may prevent or retard (chemoprocrastination) the development of spreading cancer by augmenting tumoricidal colorectal immunosurveillance mechanisms. ${ }^{28}$ This tumoricidal property may be related to the inhibition of immunosuppressive/carcinostimulant prostaglandin E2, which is produced in excessive amounts by a colorectal cyclooxygenase (COX-2) enzyme that can be induced by various mitogens including cell growth factors, cytokines, and tumour promoters. ${ }^{29} \mathrm{COX}-2$ inhibitors are attractive chemopreventive targets because selective inhibition may prevent cancer while avoiding the complications of bleeding and gastric irritation. ${ }^{29}$ These explanations emphasise the need to develop an evidence based dose related carcinogenic grading system as it is probable that low-moderate risk patients will require lower and less frequent NSAID dosing than high risk patients. Indeed, the profiling of these arbitrary risk levels challenges the validity of the epidemiological studies because it is extremely difficult to retrospectively grade baseline cancer risk levels in large populations. Furthermore, the definitions of regular aspirin use have varied between studies. Hence, the variables of cancer risk and aspirin dose/frequency have no consistent correlation and a $40 \%-50 \%$ risk reduction may reflect a net result of varying degrees of protection. For example, regular aspirin consumption in low-moderate risk, moderate-medium risk, medium-high risk, and high to carcinoma in situ cohorts could be associated with risk reductions of $80 \%, 60 \%, 40 \%$, and $20 \%$ respectively. In accordance with this principle, the American Cancer Society have called for randomised trials directed at the prevention of colorectal adenomas as precursors of colorectal cancer. ${ }^{30}$

NSAIDs and oesophageal cancer

The evidence supporting a link between NSAID use and 
oesophageal cancer is less strong. There are, however, similarities between the carcinogenic process and the chemopreventive potential of NSAIDs in these organs (Table). Oesophageal cancer is also associated with the excessive production of prostaglandin $E 2^{31}$ and two published reports have documented the ability of NSAIDs to prevent and reverse chemically induced oesophageal cancers in rodents. ${ }^{32}{ }^{33}$ Epidemiological studies, however, have produced conflicting results. Thun et al ${ }^{34}$ studied 635031 adults who, in 1982, had provided information on the frequency and duration of their aspirin use. They found a $40 \%-50 \%$ reduction in oesophageal cancer risk among regular aspirin users. A similar, albeit smaller (12 668 subjects) study by Schreinemacher and Everson ${ }^{35}$ found that aspirin consumption offered no protection against oesophageal cancer. Both studies reported an inverse correlation between aspirin consumption and colorectal cancer risk. There are, however, good pharmacological reasons to suspect that regular NSAID consumption does offer protection against oesophageal squamous cell carcinoma and adenocarcinoma. Chronic oesophagitis, an important precancerous oesophageal lesion and inflammation, is associated with the excessive mucosal production of prostaglandin E2. ${ }^{36}$ The raised prostaglandin/leukotriene ratio may contribute to carcinogenesis because prostaglandin E2 seems to be carcinostimulant in the oesophagus while lipoxygenase metabolites are protective. ${ }^{37}$ NSAIDs can prevent and reverse oesophageal inflammation, and biochemically this would parallel a restoration of the low prostaglandin leukotriene ratio associated with the normal oesophageal mucosa. NSAID intervention may be particularly useful in the areas of the world with a high incidence of chronic oesophagitis and oesophageal squamous cell carcinoma.

Barrett's oesophagus is an important precancerous lesion and is thought to represent an adaptive response to longstanding reflux injury. Barrett's oesophagus may be prevented by NSAIDs because prostaglandin E2 seems to drive the cycle of dysmotility, duodenogastric reflux, mucosal injury, aggravated dysmotility, and further duodenogastric reflux. ${ }^{36} 37$ The incidence of Barrett's related adenocarcinoma has increased recently. This may be related to a 'Western' diet rich in prostaglandin E2 precursors such as linoleic acid. High values of prostaglandin E2 can relax the pyloric and cardiac sphincters while suppressing gastric acid secretion (A M Sammon, personal communication) and the resulting non-acid duodenogastric reflux may initiate or exacerbate the vicious prostaglandin E2 cycle. Furthermore, the immunostimulatory properties of NSAIDs may be valuable as Barrett's oesophagus is associated with the depressed function of tumoricidal immune cells. ${ }^{38}$ NSAIDs could help to prevent malignant

Similarities between colorectal and oesophageal carcinogenesis

\begin{tabular}{lll}
\hline & Colorectal carcinogenesis & Oesophageal carcinogenesis \\
\hline Aetiology & Well defined & Well defined \\
Normal AA metabolism & Lipoxygenase & Lipoxygenase \\
Normal PG/LT ratio & Low & Low \\
Carcinogenic PG/LT & High & High \\
PGE2 origin & COX-2 enzyme? & Diet? \\
Function of PGE2 & Inflammatory & Inflammatory \\
& Immunosuppressive & Immunosuppressive \\
& Carcinostimulant & Carcinostimulant \\
NSAID animal studies & Over 20 & Only 2 \\
Clinical evidence & Sulindac useful in FAP & None \\
Epidemiological evidence & Consistent findings & Conflicting findings \\
Properties of NSAIDs & Immunostimulatory & Immunostimulatory \\
& Induce apoptosis & Anti-inflammatory \\
& Tumoricidal & Tumoricidal \\
Future research & Epidemiology & Epidemiology \\
& Grading system & Grading system \\
& FAP patients & Barrett's patients \\
& High risk populations & High risk populations \\
\hline
\end{tabular}

$\mathrm{AA}=$ arachidonic acid, $\mathrm{PG}=$ prostaglandin, $\mathrm{LT}=$ leukotriene. degeneration in Barrett's patients by augmenting tumoricidal mechanisms. This property may be related to the inhibition of immunosuppressive prostaglandin E2 synthesis.

\section{Objections to NSAID intervention}

Because of the major public health and economic implications of NSAID cancer chemoprevention, it is essential that all recommendations are evidence based. NSAIDs can damage the gastrointestinal tract, liver, and kidneys and thus the potential benefit would need to be balanced against the risk of adverse effects. For cardiovascular disease aspirin chemoprevention with an optimum dose of $160 \mathrm{mg}$ daily has been associated with a favourable benefit versus risk ratio. This does not, however, justify large scale aspirin chemoprevention because the doses of aspirin required for cancer protection may be greater than the antiplatelet dose. ${ }^{39}$ In the absence of an evidence dose related carcinogenic grading system, caution is required because biased messages reaching the general public may be misinterpreted. For example, advocating the benefit of aspirin without highlighting potential risk may lead to the inappropriate or excessive consumption. A multidisciplinary scientific approach is therefore required to produce evidence based guidelines before chemoprevention strategies can be implemented.

In high risk cohorts where NSAID chemoprevention trials appear justifiable, additional measures could be used to reduce the risk of NSAID toxicity. These could include the use of enteric coated aspirin, NSAIDs with excellent safety profiles such as azapropazone, or, in high risk patients, the use of selective COX-2 inhibitors such as nabumetone. ${ }^{40-42}$ Furthermore, in high risk patients requiring high or frequent doses of NSAIDs, omeprazole administration could be considered as there are reports that acidic NSAIDs can exacerbate oesophageal and colorectal inflammation. ${ }^{4344}$ Omeprazole can prevent NSAID gastroduodenal toxicity ${ }^{45}$ and this property justifies the serious consideration of an NSAID chemoprevention study in patients with Barrett's oesophagus.

\section{NSAIDs and Barrett's oesophagus}

Although omeprazole is often used in the treatment of Barrett's oesophagus the effects on adenocarcinoma risk are unclear. Regression of Barrett's oesophagus has been reported ${ }^{46}$ while others believe that omeprazole may encourage adenocarcinoma by facilitating alkaline reflux. ${ }^{47}$ Patients with Barrett's oesophagus receiving omeprazole are good candidates for NSAID chemoprevention as a number of carcinogenic biomarkers could be monitored. These include immune status and the prostaglandin/ leukotriene ratios in both the Barrett's and squamous mucosas. NSAIDs may also provide clinical benefit by arresting the underlying reflux cycle while the restoration of the low prostaglandin/leukotriene ratio associated with the squamous mucosa may encourage columnar cell regression. Barrett's oesophagus is associated with increased risks of colorectal cancer ${ }^{4849}$ and this supports the rationale for NSAID chemoprevention. Randomised controlled trials of omeprazole/NSAID versus omeprazole/placebo are therefore warranted. The NSAID sulindac would be a good choice for such trials given its success in FAP patients.

\section{Future research}

Future research programmes should assess the effects of NSAIDs upon intermediate carcinogenic markers such as immune status and prostaglandin/leukotriene ratios. Patients with FAP and Barrett's oesophagus are good 
candidates for NSAID or placebo randomised controlled trials. A carcinogenic grading system for oesophageal and colorectal cancer should define individual or population cancer risks, or both, as low, moderate, medium or high. Such a grading system should be versatile to accommodate regional risk factors, such as traditional dietary practices, and could be scored by assessing factors such as alcohol intake, age, demographics, dietary habits, genetic predisposition, and the presence or severity of precancerous lesions. The advantage of a quantifiable system is that NSAID efficacy could be monitored as a function of baseline risk, while changes in cancer risk may require proportionate increases/decreases in NSAID dosage and frequency. In anticipation of this, future epidemiological studies should consider the relation between aspirin consumption, baseline cancer risk, and resultant cancer incidence. Data from these studies will support the design of a dose related carcinogenic grading system. The design of this system will require a multi-disciplinary/multi-national approach, however, it would herald a break through in cancer prevention because evidence based NSAID intervention strategies could be implemented.

Pharmaceutical Department,

GARETH MORGAN

West Glamorgan Health Authority,

41 High Street,

Swansea SA1 1LT

\section{Addendum}

Three relevant papers have been recently published. In an epidemiological study, Funkhouser and Sharp ${ }^{1}$ noted that aspirin use decreased the risk of fatal oesophageal carcinoma by $90 \%$. Cauvin et al found that $25 \%$ of Barrett's oesophagus patients had colorectal adenomas. These patients are excellent candidates for sulindac/omeprazole studies.

Finally, NSAIDs may also be useful in the treatment of oesophageal carcinoma. ${ }^{3}$ Tumoricidal NSAIDs may induce carcinoma regression and could also help to reduce the risk of side effects from radiotherapy and surgery.

1 Funkhouser EM, Sharp GB. Aspirin and the reduced risk of esophageal carcinoma. Cancer 1995; 76: 1116-9.

2 Cauvin J-M, Goldfein D, Le Rhun $M$, et al. Muticentre prospective controlled study of Barrett's oesophagus and colorectal adenomas. Lancet controlled study of

3 Morgan GP. The potential of NSAIDs in the treatment of oesophageal carcinoma. Eur f Surg Oncol (in press).

1 Bennett A, Del Tacca M, Stamford IF, Zebro T. Prostaglandins from tumours of human large bowel. Br F Surg 1977; 35: 882-4.

2 Pollard M, Luckert PH. Indomethacin treatment of rats with dimethylhydrazine induced intestinal tumours. Cancer Treat Rep 1980; 64: 1323-7.

3 Kudo T, Narisawa T, Abo S. Antitumor activity of indomethacin on methylazomethanol-induced large bowel tumors in rats. Gann 1980; 71: 260-4.

4 Craven PA, Derubertis FR. Effects of aspirin on dimethylhydrazine induced colonic carcinogenesis. Carcinogenesis 1992; 13: 541-6.

5 Rubio CA, Wallin B, Ware J, Sueandar M, Duvander A. Effect of indomethacin on autotransplanted colonic tumours. Dig Colon Rectum 1989; 32: 488-91.

6 Pollard M, Luckert PH. Effect of piroxicam on primary intestinal tumors induced in rats by N-methyl nitrosourea. Cancer Lett 1984; 24: 117-21.

7 Skinner SA, Penney AG, O'Brien PE. Sulindac inhibits the rate of growth and appearance of colon tumours in the rat. Arch Surg 1991; 13: 541-6.

8 Waddell WR, Loughry RW. Sulindac for polyposis of the colon. $\mathcal{f}$ Surg Oncol 1983; 24: 83-7.

9 Waddell WR, Ganser GF, Cerise EJ, Loughry RW. Sulindac for polyposis of the colon. Am $\mathcal{F}$ Surg 1989; 157: 175-9.

10 Labayle D, Fischer D, Vielh P, Drouhin F, Pariente A, Bories C, et al. Sulindac causes regression of rectal polyps in familial adenomatous polyposis. Gastroenterology 1991; 101: 635-9.

11 Giardello FM, Hamilton S, Krush AJ, Piantadosi S, Hylind LM, Celano P, et al. Treatment of colonic and rectal adenomas with sulindac in familial adenomatous polyposis. $N$ Engl $f$ Med 1993; 328: 1313-6.
12 Kune GA, Kune S, Watson LF. Colorectal cancer risk, chronic illnesses, operations and medications: case-control results from the Melbourne Colorectal Cancer Study. Cancer Res 1988; 48: 4399-404.

13 Thun MJ, Namboodiri MM, Health CW Jr. Aspirin use and reduced risk of fatal colon cancer. $N$ Engl $₹$ Med 1991; 325: 1593-6.

14 Rosenberg L, Palmer JR, Zauber AG, Warshauer ME, Stolley PD, Shapiro S. A hypothesis: nonsteroidal anti-inflammatory drugs reduce the inciS. A hypothesis: nonsteroidal anti-inflammatory drugs reduce

15 Suh O, Mettlin C, Petrelli NJ. Aspirin use, cancer, and polyps of the large bowel. Cancer 1993; 72: 1171-7.

16 Peleg II, Maibach HT, Brown SH, Wilcox CM. Aspirin and nonsteroidal antiinflammatory drug use and the risk of subsequent colorectal cancer. Arch Intern Med 1994; 154: 394-9.

17 Muscat JE, Stellman SD, Wynder EL. Nonsteroidal antiinflammatory drugs and colorectal cancer. Cancer 1994; 74: 1847-54.

18 Giovannucci E, Rimm EB, Stampfer MJ, Colditz GA, Ascherio A, Willett WC. Aspirin use and the risk for colorectal cancer and adenoma in male health professionals. Ann Intern Med 1994; 121: 241-6.

19 Tosteson TD, Greenberg ER, Baron AJ. Aspirin use and reduced occurrence of large bowel adenomas. Gastroenterology 1995; 108: A39.

20 Evans JMM, McMahon AD, McGilchrist MM, White G, Murray FE, McDevitt DG, et al. Non-steroidal anti-inflammatory drugs, aspirin and colo-rectal cancer: a record-linkage case-control study in Tayside, Scotland. Gastroenterology 1995; 108: A464.

21 Logan RFA, Little J, Hawtin PG, Hardcastle JD. Effect of aspirin and nonsteroidal anti-inflammatory drugs on colorectal adenomas. Case-control study of subjects participating in the Nottingham faecal occult blood screening programme. BMf 1993; 307: 285-9.

22 Greenberg ER, Baron JA, Freedman DH Jr, Mandel JS, Haile R. Reduced risk of large-bowel adenomas among aspirin users. 7 Natl Cancer Inst 1993; 85: 912-6.

23 Odeh M. Aspirin and the risk of fatal colon cancer. Postgrad Med F 1993; 69: 2412.1.

24 Zijlstra FJ, van Dijk AP, Wilson JH. 15-HETE is the main eicosanoid formed by human colonic mucosa. Agents Actions 1992; Spec No C53-59.

25 Pugh S, Thomas GOA. Patients with adenomatous polyps and carcinomas have increased colonic mucosal prostaglandin E2. Gut 1994; 35: 675-8.

26 Zhou W, Rajeevan MS, Chow A. Aspirin and sodium salicylate induce apoptosis in HT-29 colon carcinoma cells. Gastroenterology 1995; 108: A559.

27 Pascricha PJ, Bedi A, Rashid A, Hamilton AJ, Akhtar AJ, O'Connor K, et al. Inhibition of apoptosis in familial adenomatous polyposis (FAP) and its modification by sulindac. Gastroenterology 1995; 108: A523.

28 Morgan GP, Williams JG. Therapeutic potential of aspirin in colon cancer. BMF 1993; 307: 1007-8.

29 Eberhart CE, Coffey RJ, Radhika A, Giardello FM, Ferrenbach S, DuBois $R N$. Up-regulation of cyclo-oxygenase-2 gene expression in human colorectal adenomas and adenocarcinomas. Gastroenterology 1994; 107: 1183-8.

30 Heath CW, Thun MJ, Greenberg ER, Levin B, Marnett LJ. Nonsteroidal antiinflammatory drugs and colorectal cancer Cancer $1994 ; 74: 2885-8$.

31 Botha JH, Robinson KM, Ramchurren N, Reddi K, Norman RJ. Human esophageal carcinoma cell lines: prostaglandin production, biological properties and behaviour in nude mice. $\mathcal{F}$ Natl Cancer Inst 1986; 76: 1053-6.

32 Rubio CA. Antitumoral activity of indomethacin on esophageal tumours. F Natl Cancer Inst 1984; 72: 703-7.

33 Rubio CA. Further studies on the therapeutic effect of indomethacin on experimental esophageal tumours. Cancer 1986; 58: 1029-31.

34 Thun MJ, Namboodiri MM, Calle EE, Flanders WD, Heath CW. Aspirin use and risk of fatal cancer. Cancer Res 1993; 53: 1322-7.

35 Schreinemachers DM, Everson RB. Aspirin use and lung, colon and breast cancer incidence in a prospective study. Epidemiology 1994; 5: 138-46.

36 Morgan GP, Williams JG. Inflammatory mediators in the oesophagus. Gut 1994; 35: 297-8.

37 Morgan GP, Williams JG. A comparison of the pathophysiological arachidonic acid metabolism in the gastric and oesophageal mucosa. Gastroenterology 1995; 108: A170.

38 Oka M, Attwood SE, Kaw B. Immunosuppression in patients with Barrett's esophagus. Surgery 1992; 112: 11-7.

39 Morgan GP. NSAIDs and the risk of digestive cancers. Arch Intern Med 1995; 155: $213-4$.

40 Fries JF, Ramsey DR, Singh G, Morfield D, Block DA. A re-evaluation of aspirin therapy in rheumatoid arthritis. Arch Intern Med 1993; 153: 2465-71.

41 Taha AS, Dahill S, Sturrock RD, Lee FD, Russell RI. Predicting NSAID related ulcers - assessment of clinical and pathological risk factors and related ulcers - assessment of clinical and pathological risk
importance of differences in NSAIDs. Gut 1994; 35: 891-5.

42 DeWitt DL, Meade EA, Smith WL. PGH synthase isoenzyme selectivity: the potential for safer nonsteroidal antiinflammatory drugs. Am $\mathcal{F}$ Med 1993; 95: 405-45.

43 Kaufman HJ, Taubin HL. Nonsteroidal anti-inflammatory drugs activate quiescent inflammatory bowel. Ann Intern Med 1987; 107: 513-6.

44 Heller SR, Fellow IW, Ogilvie AL. Non steroidal anti-inflammatory drugs and benign oesophageal stricture. BMF 1982; 285: 167-8.

45 Schieman JM, Behler EM, Loeffler KM. Omeprazole ameliorates aspirin induced gastroduodenal injury. Dig Dis Sci 1994; 39: 97-103.

46 Gore S, Healey CJ, Sutton R, Eyre-Brook IA, Gear MW. Regression of columnar lined (Barrett's) oesophagus with continuous omeprazole therapy. Alimentary Pharmacol Ther 1993; 7: 623-8.

47 Stein HJ, Barlow AP, DeMeester TR, Hinder RA. Complications of gastroesophageal reflux disease. Ann Surg 1992; 216: 35-43.

48 Limburg PJ, Ahlquist DA, Talley NI, Cameron AJ, Zinsmeister AR. Risk and site predominance of colorectal cancer with Barrett's esophagus: a and site predominance of colorectal cancer with

49 Howden CW, Homung CA. The risk of colon neoplasms in Barrett's oesophagus: a re-analysis of 9 controlled studies. Gastroenterology 1995; 108: A482. 